\title{
The Integration of Preschool Children with Autism Spectrum Disorder in Kindergartens of General Education
}

\author{
Elisavet Tsamoura \\ Department of Special Education, University of East London, London, UK \\ Email: etsamoura@uel.uk
}

How to cite this paper: Tsamoura, E. (2020) The Integration of Preschool Children with Autism Spectrum Disorder in Kindergartens of General Education. Open Access Library Journal, 7: e6037.

https://doi.org/10.4236/oalib.1106037

Received: December 31, 2019

Accepted: February 22, 2020

Published: February 25, 2020

Copyright $\odot 2020$ by author(s) and Open Access Library Inc.

This work is licensed under the Creative Commons Attribution International License (CC BY 4.0).

http://creativecommons.org/licenses/by/4.0/

\begin{abstract}
The purpose of this paper is to investigate the attitudes of preschool and early childhood teachers as well as the views of special education teachers on the inclusion of autism spectrum students in general education schools. The main goals of the research work are to study classroom practices, as well as to highlight the correlations of their main perceptions regarding the inclusion of children with ASD, the possible gender differences of these children as well as if the years of professional experience and qualifications of teachers have a significant influence on their academic development. The paper is structured mainly in theoretical framework. In the first part, there is a general introduction to ASD ending with 5 main research questions. Then in the second part, a detailed description of the disorders of the autistic spectrum, its general characteristics, as well as its attributes, its causes and its epidemiological evidence are presented. The third part is about education in students with ASD, the alternative teaching methods used, and the modern educational approaches. Inclusion policy in cases of children with Autism Spectrum Disorder is discussed for its placement application.
\end{abstract}

\section{Subject Areas}

Education, Sociology

\section{Keywords}

Autism, Co-Education, Inclusion, Special Education, Teaching Methods,

Teacher, Differentiated Teaching, Mainstream School, Legislative Framework

\section{Introduction}

The term autism was originally proposed by psychiatrist L. Kanner, in its at- 
tempt to characterize people who are deficient in communication. Over the years, a more detailed conceptual explanation of this phenomenon has been rendered, which makes autism a perpetual developmental disorder of the individual that causes impairment in the perception and understanding of external stimuli. As a result, the consequence of the same malfunction is the lack of the ability to develop social relationships, communication and good behavior [1]. However, the causes of autism remain unknown until now, although some scientific assumptions have been made about their origin. Possibly some of the factors are hereditary, biological, psychomotor, familial, genetic, immunological, perinatal, neuroanatomical, biochemical, brain structure differences, lack in enzymes or vitamins or/and minerals, even environmental pollution or virus infections [2]. Consequently, most researchers place greater emphasis on biological and hereditary causes, as the symptoms of autism are presented from the infancy of a human being [2]. In particular, their occurrence usually occurs around the age of two or even in its first year. During its development, some of its symptoms may change, but the key issues that make it difficult will remain unchanged throughout its human life [3].

Then, at school age, there is an increase in symptoms, such as inability to communicate, resulting in a lack of social skills [4] affecting general perceptions about interaction with other people [5]. These characteristics are more pronounced in the classroom as autistic children tend to skew. In addition, they exhibit a significant lack of attention during the lesson and quirky behaviors that require special treatment by classroom teachers [6]. However, research has shown that the cognitive level of children with specialties attending general school is increasing, as opposed to those attending specialties [7].

Therefore, it is evident that the Greek education system is unable to manage the issues of integration of students with autism into general education [8]. In particular, it focuses mainly on the cognitive field, defies the cultural and social complexity that is present in social reality itself. According to research reported in Cassidi's study, they conclude that it is necessary to make significant changes to it, as it fails to provide equal opportunities for children. It is noteworthy that, for the most part, children with autism spectrum who have been involved in integration courses in primary education are transferred to special education schools in secondary education, but fail to complete the integration process. However, there are some cases where, with the common consent of the school and the teacher, children with autism can attend a general school with the assistance of a special educator, without interrupting the parallel support structures provided to them [8]. For this reason, educational methods need to be wellstructured so as to enhance students' acceptance into mainstream schooling and to adequately inform the adults involved so that their psychological and social integration can be properly achieved [9].

Studies have shown that frequent contact of particular children with their peers can bring about positive changes in their emotional perception and self-image. In addition, the association of children with autism spectrum with 
typical developmental children has been shown to bring them social respect, improved friendships, and enhanced playmaking skills, as opposed to students attending special schools. However, according to a study by [10], it is concluded that "physical proximity, which includes the coexistence of students with disabilities with their peers, does not necessarily guarantee the social integration of these students, but is the first step towards integration of students with special needs in the educational and social environment of the school" (p. 2). For this reason, a number of conditions have been put in place on which inclusive education techniques are structured to produce positive results, such as the importance of frequent communication between teachers about their teaching methods and ways of administering them. It is also necessary to make use of all available resources to support learning as well as the school's human resources to maximize the effectiveness of various strategies [11].

In conclusion, it has been found that different inclusion programs for children with disabilities can provide them with a variety of teaching methods that will focus primarily on improving problem behaviors but also on enhancing communication, social behaviors and school skills [12]. However, it has not yet been identified which strategies teachers are most likely to use and which ones produce the most positive results.

In particular, the main purpose of this research is to explore the appropriate ways and strategies for more effective integration of autistic children into mainstream education. Specifically, the following main research questions are investigated:

* What are the basic perceptions of Special Preschool Educators about the inclusion of children with Autistic Spectrum Disorder in the classroom of the Standard Kindergarten?

* Is there a correlation between the basic perceptions of the inclusion of children with ASD with the gender, years of professional experience and teacher qualifications?

* What are the views of Preschool Specialists on the expected outcomes of inclusion of children with Autism Spectrum Disorder in the Standard Kindergarten classroom?

* What are the classroom practices applied?

* Is there a correlation between basic perceptions, expected outcomes, and practices applicable to the inclusion of children with ASD in Standard Preschools?

\section{Theoretical Framework}

\subsection{Autistic Spectrum Disorders}

Initially, the word "autism" comes from the word "eautos" (greek origin), symbolizing the isolation of a person in himself. It was first proposed by the psychiatrist Eugen Bleuler in 1911, which termed people with schizophrenia as having lost touch with reality. Then, in the early 1940s, the importance of autism 
changed character, following the research of psychiatrist Leo Kanner and pediatrician Hans Asperger, who identified autism based on a number of cases of children with impaired social development, unusual language impairment and unusual language development. A few years later in 1976, psychiatrist Lorna Wing presented the "Trinity of Disorders" and the difficulties faced by people with autism in the stages of socialization, communication, and imagination [13]. Consequently, the created disorders are caused by certain brain malfunctions and are classified as difficulties in social interaction, verbal and non-verbal communication, as well as repetitive behaviors. Following the creation of the DSM-5 Diagnostic Manual of May 2013, all autistic disorders were renamed "Autistic Spectrum Disorders". Therefore, the different types included in the term autism, such as autistic disorder, diffuse developmental disorder and Asperger's syndrome, were separated. Consequently, Autistic Spectrum Disorders (ASD) includes intellectual disability, difficulties in coordinating movements and attention, sleep disturbances or even gastrointestinal disorders. It is important to note that although people who are diagnosed with autistic spectrum disorders appear to be disadvantaged in these areas, they still benefit from others such as music, mathematics, art, and have increased visual abilities.

Therefore, it is observed that autism interferes with the way information is processed by the brain, modifying, in an obscure way, the energy of nerve cells and their interconnections [14].

\subsection{Definition-General Features}

Autism manifests itself in various forms, both in intensity and in the way it manifests itself, as there are factors such as mental and linguistic levels that determine its character, intensity, and frequency. In addition, the properties of autism change over time due to the development and neurological maturation of the individual, as well as due to the environmental influences, social experience and education received [15].

One of the main effects of the autistic spectrum is the lack of social interaction skills, as people with autism have insufficient attention to their surroundings and do not seek contact, not even physical and physical contact. More specifically, these individuals exhibit a lack of interaction initiatives and do not respond to peer or adult prompts for social interaction. They also continue to rely mainly on communication gestures in both preschool and school age, and often use the body of others as a tool to fulfill their own weaknesses. In addition, it is observed that children with autism have an unusual reaction in the presence of other peers, as they are not particularly interested in playing and generally interacting with them, but in contrast their main reaction is panic. The issue of the inexperience of social interaction with people of the same age is not eliminated as long as it continues to manifest itself, even when children are now beginning to interact with adults. It is worth noting, however, that in cases of improved social interaction, these individuals are prevented from acquiring basic social skills [15]. Moreover, self-regulation problems are frequent to students diagnosed with 
ASD [16].

In particular, children who have autistic spectrum disorders primarily behave as if there were no other people around them, cannot be approached when shouting at them, avoid eye contact and usually do not want any physical contact. In addition, they only express emotions when they feel greatly anger, anxiety or joy, they lack of empathy and understanding of others' thoughts and are likely to become difficult and/or aggressive if not given the attention they seek. Usually, though they are alienated in their own world, they are open to social approaches, as long as the interaction is initiated by the other person and they are willing to follow instructions [12].

In conclusion, the weakness caused by the autism disorder is more qualitative than quantitative; these individuals themselves react to their environmental stimuli, simply in their own unique way or even slower. In addition, they do not show apathy for others as they realize that each person means something different to them. This is demonstrated by the attachment of these children to parents or other familiar persons, but also by the change in their behavior depending on the circumstances and the persons in contact. Finally, they recognize their mirror image, which shows that their social disadvantage is not due to their inability to distinguish themselves from others [15].

\subsection{Causes of Autism}

Various theories about the causes of autism have been published at times, but due to the methodical study of the last ten years, the biological basis of his disorders has been presented. This discovery influenced the therapeutic approaches and made it even more difficult to find a specific cause. Therefore, according to researchers, there are several theories, each attributing to different factors the creation of autistic syndrome [17].

In particular, gene changes or mutations associated with ASD have been discovered, and more than 100 genes that are fearful for autistic spectrum have been presented. In addition, its presence may also be due to genetic causes, although the majority of causes are due to combinations of genetic and environmental factors that interfere with brain development [18]. In addition, organic, hereditary, and psychogenetic factors play a key role in cause theory. In more detail, the organic factors, where autism is conferred, include distortions of the brain from organic or metabolic causes. But this theory has not been fully accepted, as there are not enough samples, and it cannot explain the autism of children who do not have brain damage. On the contrary, the theory based on hereditary factors is that children with autism came from families with psychological disorders. However, there is enough data to almost undermine the existence of the same view, as the majority of children with autism come from parents with a high level of cognition, without psychopathological disorders, and it is also very rare to have a second autistic child in the family [17].

Therefore, according to recent information no known cure for autism has been established. However, there has been great progress in understanding both 
the particular quality of characteristic and the cognitive differences. Thus, multiple psycho-educational interventions have been devised which contribute to the improvement, independence and quality of life of the individual and the family [17].

\subsection{Epidemiologic Data}

The epidemiology of autism spectrum disorders has attracted the interest of many researchers as regular rates of its presentation are increasing at regular intervals. In more detail, studies conducted in the 1970s showed that six in nine cases out of 10,000 people suffer from autism spectrum, and 12.25 out of 10,000 people have atypical autism. Also, 16.8 in 10,000 infants mainly have autistic disorder and 45.8/10,000 other developmental disorders. In addition, boys have a higher morbidity rate compared to $3.5 / 1$ to $4 / 1$ girls [19]. It is important to note that $23 \%$ of people with autism are highly functional, while $50 \%$ have moderate to mild mental retardation and $27 \%$ have severe mental retardation [20].

\section{Education of Students with ASD}

Since 1943 the education and therapeutic approaches of people with autism have been modified several times. In the past, educating a child with autism took place in specialized training units or psychiatric clinics. Then, as new data emerged year after year and great progress was made in the knowledge of autism disorder, the inclusion and integration of these children into mainstream education are no longer considered irreparable [8]. In particular, it was not until the 1960s that children with autism are considered that they could not be educated. However, after several actions, psychologist Ivar Lovaas and his colleagues developed a methodical treatment program based on the principles and modes of Behavioral Analysis. This program highlighted the development of different reactions and abilities in which children with autism were inefficient [15].

It is important to note that the inclusion of children with special educational needs such as autism in the general education units does not only aim at the effective therapeutic process of these children, but mainly the acceptance and coexistence of people with disabilities or/and special needs with people of typical development (Pena, 2008) [21]. However, this can only be achieved by producing positive results only when using different approaches and specific models of education tailored to children with special educational needs [22].

\subsection{Differentiated Teaching}

One model of education that is considered effective in educating and integrating children with autism or in general with special educational needs is Differentiated Teaching. More specifically, it is an educational ideology that aims to change the way of teaching from the predetermined Curriculum and is based on the needs of the students. Therefore, teachers should reformulate the way knowledge is conveyed according to each level and the interests of their students. 
Practically, it is a concept that encompasses a variety of teaching methods and special aids focused on the student and learning. In addition, it seeks to develop a flexible learning environment, where the different abilities of children will be promoted and exploited to direct knowledge, while providing them with equal opportunities. Consequently, students learn not only to rely on their own abilities, but also to truly communicate and collaborate with each other [23].

In the context of special education, the involvement of students with special needs and the use of differentiated teaching have always been functional. However, although there are now social and cultural arrangements for students in mainstream schools, the use of single teaching is considered inappropriate and ineffective. Therefore, promoting inclusion of students with disabilities in mainstream education classrooms increases internal differentiation in formal classes [24].

\subsection{Contemporary Educational Approaches}

Every European country has implemented many different educational programs for students diagnosed with autism. However, there are some that stand out as they appear to be more positive in improving the abilities of these children than others. However, there are significant shortcomings in detailed research that would suggest a comprehensive proposal for the use of a specific program.

More specifically, these programs contain various types of teaching systems that are tailor-made to enhance legitimate behaviors and to change key problem behaviors. In addition, many experts argue that behavior management should be complemented by an organized teaching of skills, in order to normalize the difficulty of acquiring linguistic, communication, social and other behavioral skills. Therefore, effective behavior management programs offer improvement in problem behaviors, enhance communication, social learning and school competencies. They also contribute to the education of all children with autism and contribute to the integration of children with autism into general education units so that children of typical development can act as role models.

One of the approved educational programs is TEACCH (Treatment \& Education of Autistic and Related Communication Handicapped Children). This method is based on structured education, which creates an expected environment where the child with autism will feel at home and act safely. Specifically, it aims to develop the autonomy of these children themselves using personalized teaching, focusing on the perception and proper guidance of their individual traits.

Once the child's attributes are recognized, then his/her education begins in several, functional, clearly organized and structured contexts with a key factor in visual media, such as picture programs. In addition, behavioral processes are implemented, using alternate forms of communication such as symbols and chiropractors [12].

Another sophisticated training program is the Alternative Picture Communication System, also known as PECS (Picture Exchange Communication System-PECS). In particular, it is observed that a respectable proportion of children 
with autism have severe verbal impairments, which makes them unable to express their needs immediately. Consequently, the creation of a communication system is considered essential for one's autonomy and promotes its adaptation to the social environment. It also gives children with autism the opportunity to take communication initiatives using images. It is important to note that this system is made up of seven hierarchical periods in which the child is taught how to approach and give one of the images depicting a desired object to the adult. After this conquest, he will be able to select some images of desired objects from a dashboard and then form and use simple picture phrases. Therefore, by going beyond these basic stages, the child will be able to extend their sentences and include verbs or even more complex concepts such as colors, shapes and sizes [25].

The distinguished programs could not fall short of the method of Social Stories. Essentially, this is a way of teaching that helps to enhance social skills in the realm of autism spectrum disorders. More specifically, children with autism per period follow personalized short stories that help them understand using challenging vocabulary and concepts of challenging or inappropriate social situations-behaviors that they engage in daily [26]. According to Gray (2000), as quoted in a research by Ferko (2011) [26], "Stories have a precise definite style and shape. They describe the relevant social messages of a situation from the point of view and perspective that each child encounters with others, and often suggest an appropriate response to improve their behavior. A social story is a simple description of the daily social situation written from a child's perspective" (p. 21). Finally, they are considered to be suitable for anchoring the child to various peculiar situations and to normalize them [26].

The educational approach of students with autism through music is also noteworthy. The so-called "music therapy" mainly contributes to the improvement of their sensory and motor abnormalities. Moreover, it is of particular interest to them and at the same time a means of expression. It is important to note that these children are disadvantaged in understanding facial expressions, gestures, and other people's postures. Consequently, by engaging in music production and songwriting, they develop pleasant emotions and increase their self-esteem. It also helps and facilitates memorization of words, enhances their understanding of themselves, and benefits them in broadening their skills [27].

\section{Inclusion of Students with ASD in the Mainstream School}

In Greece, the first reference to inclusive education is made in 2008, according to Law 3699/2008 [28]. The issue of people with disabilities and their education has been formulated according to their time and social beliefs. One of the most important events that have been noted is that the teaching of students with disabilities was conducted in older times in institutions and accommodations, as opposed to the modern age, where respect and understanding of particularity was established, as well as the introduction of inclusive education, that includes all children in the class, without discrimination.

It is important to note that the alienation of children with special needs, such 
as students with autism spectrum disorder, from school contributes to their copyright infringement [29]. Moreover, the documentation of this theory is complemented by the seemingly inadequate predisposition of the educational community to its structure. In particular, the actions of the system are discernible, which impede the integration of these students into general education, such as the rigid national curriculum, the immediate delivery of lessons and the method of evaluating children, which do not allow the modern alternation of course delivery. In addition, teaching resources are poorly used, with the result that teaching is documented only through books [30]. Consequently, due to the inadequacy of the school community in integrating children with special needs, emphasis is placed on their involvement in specialized learning activities, their engagement in peer groups and free play. However, the immediate integration of new technologies, as well as the appropriate training that each teacher must receive, is essential for the promotion of education [31].

As a result, the inadequate implementation of children with autism in mainstream schools is considered to be due to the lack of planning for a new social policy that will have their acceptance and effective integration into school reality. These actions clearly also need the right environment to take advantage of, such as the conversion of school buildings and new curricula specifically modified for students with different conditions [32]. It is worth noting that the programs themselves should follow an organized approach, which will gradually strive to achieve an outcome [33].

Equally important is the role of the teacher as it contributes to the process of educating students with special educational needs while creating appropriate ways of integrating and adapting to the general classroom of the school. Therefore, in order to achieve these goals, it is necessary for the educator to have a positive attitude towards the idea and implementation of inclusive education, as well as with children with autism, but also with special needs in general, to which he/she must show respect and include in the teaching process their personal peculiarities. In addition, in order to fulfill the integration of these students, it is important to have some basic knowledge of special education in order to be able to convey this behavior to other students as well. It should also maintain a cooperative spirit, because inclusive education requires the cooperation of all those involved in this educational process, such as speech therapists, occupational therapists, social workers, pediatric psychiatrists, school nurses and special educators for the exchange of ideas, opinions and the best solution to the problems presented [34].

\section{Legislative Framework for the Education of Students with ASD}

Human rights are an ideal basis for the development of shared freedoms, as well as for the security of human life and dignity. They are indivisible, interconnected and interdependent. They aim to ensure equal opportunities and the free will of every person. Children, as one of the most important social actors, are often a vulnerable group that the State must protect, as their rights are violated in every 
way [35].

Children with disabilities in particular are one of the minority groups that frequently encounter problems in their daily lives and especially in education. The position of the UN Social and Economic Council is remarkable as noted in [36] for people with disabilities. In particular, it states that "a person with a disability is considered to be unable to provide for himself or herself in any or all of the needs of a normal individual or social life because of a congenital or acquired physical or mental handicap" (p. 10). For this reason, people with disabilities need special treatment as, according to the Law (Article 1, Law 2817/2000) [37], they may have learning difficulties and integration problems due to their particularities. Consequently, there is a need for the presence and support of social welfare, which must provide them with medical coverage, as well as a smooth integration into social activities [38].

Subsequently, the new wording of Law 3699 [28] as set out in Article (3) defines those with disabilities to be those with learning disabilities due to sensory, cognitive, cognitive, developmental problems, and those with mental and neuropsychiatric disorders that affect the process of school adaptation and learning. Also, people with disabilities and special educational needs are mainly those with intellectual disabilities, sensory and/or hearing impairments, motor problems, chronic non-communicable diseases, speech disorders and learning disabilities, but not caused by external factors. Also included are people with autism spectrum, mental disorders and multiple disabilities, as well as so-called charismatic children, that is, children with one or more mental abilities (Article 3, Law 3699/2008) [28]. In addition, the passage of this law led to a number of reforms that allowed them to be given equal rights in terms of their involvement and contribution to society, to an independent way of life, to economic sufficiency and authoritarianism, and to the full realization of their rights as far as education, social and occupational integration are concerned. Moreover, in the context of Special Education, the term of education is added, with the aim of providing appropriate educational services and facilities for students with disabilities and/or students with special educational needs (Article 1, Law 3699/2008) [28]. It is important to remember, and the placement of the United Nations (2010) in Article 24, which says that all children have the same rights and each State must recognize. More precisely, it refers to the theorem of inclusion, which wants people with disabilities to have access to general education schools that respond to the needs of children and at the same time provide them with appropriate support in order to increase their academic [38] [39] [40] [41] and social development (United Nations, 2010).

Therefore, the state must maintain and uphold the basic style of special education and training as an integral part of compulsory and free public education, as well as ensure that free public special education and training is provided to people of particular age, as well as their educational degrees (Article 1, Law 3699/2008) [28]. 


\section{Theoretical Methodological Approach}

For the proper use of educational research, the methodological approach taken in this study is quantitative. Specifically, this method was chosen because the researcher can initially deepen in the personality of the collaborating individuals and understand their social and ideological views on the subject under consideration, in order to clarify their data without distorting and derive its conclusions (Paraskevopoulou, 2008) [42]. In addition, by using the quantitative method, the researcher is able to gather objective and vague information about a phenomenon and then modify it into figures or statistics to compare the various variables and produce objective results for the causes or their similarities, which would constitute an objective and general theory of research (Mantzoukas, 2007) [43].

More specifically, two hundred questionnaires were used to provide teachers with an accurate distribution of events (Parkos, Dafermos, 2010) [44]. In addition, because of the large sample access, the results can be varied and objectified, as well as with greater accuracy (Cohen, Manion, 1980) [45]. It is important to note that using this method itself results in higher validity and reliability of research results, as its techniques best reflect human behavior.

\section{Limitations \& Future Suggestions}

One limitation is related to gap existed in bibliography related to the issue of integration of children with ASD in Mainstream schools. It's beyond any doubt that time passes and new theories or methods come up. Given the insufficient research data in the field of ASD in Greece, the conclusions drawn from this study are considered important and are expected to enrich the scientific research and trigger new studies. The research data can be considered for a future enrichment through further pilot research with the exploitation of information and through quality research methods. Valuable material and essential feedback can be derived from interviews with special educators, thus achieving a thorough collection of qualitative data.

\section{Acknowledgements}

This study would not have been possible without the contribution of numerous people. We would like to thank the educational staff who took part in the research.

\section{Conflicts of Interest}

The author declares no conflicts of interest regarding the publication of this paper.

\section{References}

[1] Zois, G. and Dimitrakopoulos, S. (2004) Handbook of Parenting Support for Parents with Autistic Children.

http://www.specialeducation.gr/frontend/article.php?aid=168\&cid=72 
[2] Papagalou, A. (2014) Therapeutic Interventions in Autistic Spectrum Disorder: A Literature Review. Department of Speech Therapy, Technological Educational Institute of Epirus. http://apothetirio.teiep.gr/xmlui/handle/123456789/756

[3] Tzoumailis, A. (2014) Diffuse Developmental Disorders Sensory Integration and Alternative Treatment Methods. Department of Speech Therapy, Technological Educational Institute of Epirus.

http://apothetirio.teiep.gr/xmlui/bistream/hadle/123456789/495/lgt_2014012.pdf?se quence $=1$

[4] Pallikara, N. (2017) Autism, Toys and Drama Therapy. Undergraduate Thesis, Department of History Methodology and Theory of Science, National and Kapodistrian University of Athens, Athens.

https://pergamos.lib.uoa.gr/uoa/dl/frontend/file/lib/default/data/1399274/theFile

[5] Bania, T.A., Antoniou, A.S., Theodoritsi, M., Theodoritsi, I., Charitaki, G. and Billis, E. (2019) The Interaction with Disabled Persons Scale: Translation and Cross-Cultural Validation into Greek. Disability and Rehabilitation, 1-8. https://doi.org/10.1080/09638288.2019.1643420

[6] Giora, G.H. (2017) Basic Principles for the Design and Implementation of a Personalized Living Education Program for Individuals with ASD-Case Study. Postgraduate Thesis, Department of Education and Social Policy, School of Social, Humanities and Arts, University of Macedonia, Macedonia. https://dspace.lib.uom.gr/bitstream/2159/20632/4/GioraGkolfoIlianaMsc2017.pdf.pdf

[7] Tzimas, G. and Lambropoulou, A. (2007) From Integration into Inclusion and Co-Education of Deaf Children in the Common School. Proceedings of the 4 th Panhellenic Conference with International Participation "Equal School for Children with Disabilities", Hellenic Institute of Applied Education and Education, Athens, 4-6 May 2007, 241-247.

https://www.elliepek.gr/documents/4o_synedrio_eisigiseis/241_247.pdf

[8] Stellatou, A. and Mallopoulos, H. (2016) Educational Approaches to Teaching Children with Autism. Proceedings of the 6 th Panhellenic Conference with International Participation in "Education Sciences and Special Education", National and Kapodistrian University of Athens, Athens, 23-26 June 2016, 1208-1215.

https://eproceedings.epublishing.ekt.gr/index.php/edusc/article/dowload/1006/1182

[9] Ramouzi, E. (2014) Children with Autism in Secondary Education. The Perspective and Experience of Educational and Social Workers. The Case of a School. Postgraduate Thesis, Democritus University of Thrace, Alexandroupoli.; http://repo.lib.duth.gr/jspui/bitstream/123456789/10354/1/Ramouzi.pdf

[10] Triga, E. (2010) The Issue of Inclusion of Children with Special Educational Needs in Kindergarten. Proceedings of the 5 th Panhellenic Conference with International Participation "I Learn How to Learn", Athens, 7-9 May 2010, 17-29. http://www.elliepek.gr/documents/5o_synedrio_eisigiseis/Trigka_Eleni.pdf

[11] Antoniou, A.S., Geralexis, I. and Charitaki, G. (2017) Special Educators' Teaching Self-Efficacy Determination: A Quantitative Approach. Psychology, 8, 1642. https://doi.org/10.4236/psych.2017.811108

[12] Tsamitrou, E. (2010) Intervention Program to Enhance Interaction between Children with Autism and Their Siblings: A Case Study. Postgraduate Thesis, Department of Educational and Social Policy, Postgraduate Special Education, University of Macedonia, Macedonia. https://dspace.lib.uom.gr/bitstream/2159/13989/1/Tsamitrou_Msc2010.pdf

[13] Papadimitriou, A. (2011) Inclusion of Children with Autism in the Classroom of 
General Education. Undergraduate Thesis, University of Thessaly, Thessaly. http://ir.lib.uth.gr/bitstream/handle/11615/41135/9589.pdf?sequence=1

[14] Kapsalis, N. (2015) Development of Educational Software for Language Development of People with ASD and MI (=Mental Impairment). Diploma Thesis, National and Kapodistrian University of Athens School of Philosophy Department of Linguistics, National Technical University of Athens School of Electrical and Computer Engineering Department of Control and Robotics.

http://glotta.ntua.gr/courses/Technoglossia/Dissertations/teliko_keimeno_diplwmat ikhs_Kapsalis.pdf

[15] Galanis, P. (2009) Educating Children with Autism in Self-Management: A Behavioral Analytical Intervention for School Integration. Doctoral Thesis, National \& Kapodistrian University of Athens, School of Philosophy, Department of Philosophy-Pedagogy-Psychology, Department of Pedagogy. http://thesis.ekt.gr/thesisBookReader/id/24403\#page/1/mode/2up

[16] Charitaki, G., Soulis, S.G. and Tyropoli, R. (2019) Academic Self-Regulation in Autism Spectrum Disorder: A Principal Components Analysis. International Journal of Disability, Development and Education, 1-20. https://doi.org/10.1080/1034912X.2019.1640353

[17] Dimitriou, I., Kosmou, A. and Kyriazi, D.B. (2014) Autism Spectrum Disorders: Views of Special Education Teachers and Special Education Staff on the Education of Children and Adolescents in Heraklion Prefecture. Thesis, Technological Educational Institute of Crete, School of Health Care Professions, Department of Social Work. https://apothesis.lib.teicrete.gr/handle/11713/1084

[18] Rizou, A. (2017) General and Special Education Teachers' Perceptions of Secondary and Primary Education for Children with Autism Spectrum Disorder. Postgraduate Thesis, University of Macedonia, Macedonia. https://dspace.lib.uom.gr/handle/2159/21088?locale=en

[19] Asonitou, Grigoriou, F., Kaklamanaki, E., Kourti, B., Magaliou, E., Mitropoulou, E., Paizi, O., Tsakpini, K., Tsiouri, I., Tsirabidou, M. and Karzi (2003) Curricula for Students with Autism.

http://www.pi-schools.gr/special_education/aps-depps-autismos.pdf

[20] Penna, A. (2008) Teacher Attitudes and Readiness for Inclusion of Children with Special Educational Needs in the Mainstream School. PhD Thesis, University of Western Macedonia, Kozani. http://thesis.ekt.gr/thesisBookReader/id/17777\#page/1/mode/2up

[21] Charoupias, A. (2003) The Equal Co-Education (Inclusion) University of Ioannina, School of Education, Laboratory of Special \& Therapeutic Education (EPE), European Union-European Social Fund, Ministry of National Education \& Religious Affairs.

http://imm.demokritos.gr/epeaek/library_attach/20041261621220.CharoupiasPart_ 2-1.pdf

[22] Mantzaridou, A. (2018) Training-Educational Material with Principles and Examples of Differentiated Teaching in Foreign Language Education. Ministry of Education, Research and Religions, Institute of Educational Policy. https://www.iep.edu.gr/moodle/mod/resource/view.php?id=1213

[23] Panteliadou, S. and Antoniou, F. (2008) Teaching Approaches and Practices for Students with Learning Disabilities. Volos.

[24] Autistic Spectrum Disorder Guide (2015) Applying the Principles of Differentiation in Special Education. 
https://prosvasimo.gr/docs/odigos_diaforopoiisis/.../Guide $\% 20 \Delta \mathrm{A} \Phi \% 20$ (final)pdf

[25] Ferko, K. (2011) Using Social Stories through Computers to Improve Real-World Skills in Children with Autism Spectrum Disorders. Undergraduate Thesis, TEI of Patras, School of Health Professions and Welfare, Department of Speech Therapy. http://www.lib.teipat.gr/ptyxiakes/seyp/seyp_log/2011-2014/9554pe.pdf

[26] Garani, S. (2008) Autism and Play: A Pilot Study of Recording and Investigating the Views of Educators, Specialty Representatives (Teachers, Speech Therapists, Occupational Therapists, Psychologists, Social Workers) and Parents about the Use of Play in the Education and Treatment of Children with Autism. Postgraduate Thesis, University of Macedonia Economic and Social Sciences, Department of Education and Social Sciences.

https://dspace.lib.uom.gr/bitstream/2159/12515/2/GaraniMsc.pdf

[27] Hellas. Special Education and Training of Persons with Disabilities or Special Educational Needs. Law 3699/2008. National Printing Office, Athens. https://www.noesi.gr/book/law/nomos-eidikis-agogis-3699-2008

[28] Efstathiou, M.A. (2010) The Contribution of KDAY and KEDDY to the Integration of Persons with Disabilities and Individuals with Special Educational Needs into the Greek Education System, by Minas Efstathiou. Contemporary Education, No. 161. https://id.scribd.com/document/292592012/\%CE\%97-\%CE\%A3\%CF\%85\%CE\%BC \%CE\%B2\%CE\%BF\%CE\%BB\%CE\%AE-\%CE\%A4\%CF\%89\%CE\%BD-\%CE\%9A\%C E\%94\%CE\%91\%CE\%A5-\%CE\%9A\%CE\%B1\%CE\%B9-\%CE\%A4\%CF\%89\%CE\%B D-\%CE\%9A\%CE\%95\%CE\%94\%CE\%94\%CE\%A5-\%CE\%A3\%CF\%84\%CE\%B7\%C E\%BD-\%CE\%88\%CE\%BD\%CF\%84\%CE\%B1\%CE\%BE\%CE\%B7-\%CE\%A4\%CF\%8 9\%CE\%BD-\%CE\%91\%CF\%84\%CF\%8C\%CE\%BC\%CF\%89\%CE\%BD-\%CE\%9C\%C E\%B5-\%CE\%91\%CE\%BD\%CE\%B1\%CF\%80\%CE\%B7\%CF\%81\%CE\%AF\%CE\%B

[29] Lampropoulou, B. and Pandeliadou, S. (2010) Special Education in Greece-Critical Theory. http://www.dyslexia-goneis.gr/view.asp?ItemID=109\&ns=1\&mcid=9\&cid=23\&scid=16

[30] Vlachos, D. (2008) The Pedagogical Institute and Contemporary Requirements in Education. http://repository.edulll.gr/edulll/handle/10795/99

[31] Strongylos, B. and Xanthakou, G. (2007) At an Equal School for Unequal Children: Integration and Interdisciplinary Collaboration. Proceedings of the 4 th Panhellenic Conference with International Participation "Equal School for Unequal Children", Hellenic Institute of Applied Education and Education, Athens, 4-6 May 2007. http://www.elliepek.gr/documents/4o_synedrio_eisigiseis/324_330.pdf

[32] Tzouriadou, M. (2008) Curriculum Adaptations for Students with Learning Disabilities. Theoretical Framework. Curricula for Learning Difficulties-InformationAwareness, Ministry of National Education and Religious Education Institute. http://repository.edulll.gr/edulli/handle/10795/957

[33] Arvanitidou, K. (2018) The Attitudes of Primary and Secondary Education Teachers Regarding the Inclusion of Students with and without Disabilities in Mainstream Schools. Postgraduate Thesis, School of Social, Humanities and Arts, Department of Education and Social Policy. https://dspace.lib.uom.gr/bitstream/2159/22094/3/ArvanitidouKatifeniaMsc2018.pdf

[34] Sourlas, I.G (2014) 2015-2020 Children's Rights Action Plan. https://www.opengov.gr/ministryofjustice/wp-content/plugins/download.../downlo ad.php

[35] Kourtesi, S. (2013) Social Exclusion and People with Disabilities. Sociological Theory. Aristotle University, School of Pastoral and Social Theology Department, 
Law, Organization, Life, and Ministry. http://ikee.lib.auth.gr/record/134331/files/GRI-2014-12356.pdf

[36] Hellas. Education of People with Special Educational Needs and Other Provisions. Law 2817/2000. National Printing Office, Athens. http://www.eedip.tuc.gr/fileadmin/users_data/eedip/nomoi/N2817_2000.pdf

[37] Vardakastanis, I., Gounari, E.M., Logaras, D., Barbalia, E., Pananos, A., Skordilis, A., Soulis, S., Chatzipetrou, A. and Christofi, M. (2008) Designing Disability Policy. Student Handbook. National Confederation of Persons with Disabilities. http://repository.edulll.gr/edulll/handle/10795/1050

[38] Charitaki, G., Baralis, G., Polychronopoulou, S., Lappas, D. and Soulis, S.G. (2014) Factors Related to Numerical Ability of Children with Down Syndrome. The International Journal of Early Childhood Learning, 29, 407-431. https://doi.org/10.18848/2327-7939/CGP/v21i01/48429

[39] Charitaki, G., Baralis, G., Polychronopoulou, S., Lappas, D. and Soulis, G.S. (2014) Early Numeracy in Children with Down's Syndrome in Greece. Psychology, 5, 1426-1432. https://doi.org/10.4236/psych.2014.512153

[40] Charitaki, G., Baralis, G., Polychronopoulou, S., Lappas, D. and Soulis, G.S. (2015) Difficulty in Learning to Count or Effect of Short-Term Memory Deficiency in Mathematical Abilities? International Journal of Innovation and Research in Educational Sciences, 2, 60-62.

[41] Baralis, G., Soulis, S., Lappas, D. and Charitaki, G. (2012) Providing Students with Mild Mental Retardation the Opportunity to Solve Division Problems Related to Real Life. HMS International Journal for Mathematics in Education, 4, 195-206.

[42] Paraskevopoulou-Kollia, E.-A. (2008) Methodology of Qualitative Research in Social Sciences and Interviews. Open Education: The Journal of Open and Distance Education and Educational Technology, 4, 72-81.

[43] Mantzoukas, S. (2007) Qualitative Research in Six Easy Steps. Epistemology, Methods and Presentation. Review, 46, 88-98.

http://openworkshop.pbworks.com/w/file/fetch/64390801/6-bhmata-poiotikh-ereyn a.pdf

[44] Parkos, M. and Dafermos, M. (2010) Qualitative Research in Psychology and Education: Epistemological, Methodological, and Ethical Issues. Scientific Publications, New York.

[45] Cohen, L. and Manion, L. (1980) Research Methods in Education. Croom Helm Ltd., Educational Research Methodology, London. 